\title{
COMPARACIÓN DE LA ECOTOXICIDAD POR METALES PESADOS SOBRE BACTERIAS HETERÓTROFAS DE DOS SITIOS CONTRASTADOS DEL LAGO DE MARACAIBO (VENEZUELA)
}

\author{
COMPARISON OF HEAVY METAL ECOTOXICITY ON HETEROTROPHIC \\ BACTERIA FROM TWO CONTRASTED SITES AT THE LAKE MARACAIBO (VENEZUELA)
}

\section{Fernando Luis CASTRO ECHAVEZ ${ }^{*}$, Julio César MARÍN LEAL²}

${ }^{1}$ Centro de Investigaciones, Universidad de la Guajira, Km 5 vía Maicao, Colombia.

${ }^{2}$ Departamento de Ingeniería Sanitaria y Ambiental (Disa), Escuela de Ingeniería Civil,

Facultad de Ingeniería, Universidad del Zulia, CP 526, Maracaibo 4011-A, Venezuela.

*Autor corresponsal. E-mail: fcastro@uniguajira.edu.co
Historia del artículo

Recibido: Mayo 12, 2017

Evaluado: Julio 4, 2017

Aceptado: Julio 18, 2017

Disponible: Agosto 28, 2017

\section{Resumen}

La contaminación del sistema estuarino lago de Maracaibo (Venezuela) representa un problema ambiental de vieja data que lo ha convertido en un ambiente hipereutrófico afectado por distintas fuentes contaminantes, lo cual ejerce una fuerte presión de selección sobre los organismos que allí habitan. En el presente trabajo se comparó la ecotoxicidad por metales pesados $\left(\mathrm{Cr}^{+3}, \mathrm{Cr}^{+6}, \mathrm{Cd}^{+2}, \mathrm{Ni}^{+2}\right.$ y $\left.\mathrm{Pb}^{+2}\right)$ sobre bacterias heterótrofas de dos sitios contrastados del lago de Maracaibo, 1) Vereda del Lago y 2) Puerto Concha, mediante la estimación de la concentración mínima inhibitoria (CMI) y la concentración de inhibición para el 50 \% de la población de ensayo $\left(\mathrm{CL}_{50}\right)$. Para ello, se usó el método de difusión en discos de papel, midiendo el halo de inhibición del crecimiento después de $24 \mathrm{~h}$. Las estimaciones de $\mathrm{CL}_{50}$ se realizaron por análisis Probit. Las cepas bacterianas aisladas de aguas superficiales mostraron alta resistencia a los metales pesados ensayados, con valores de $C M I$ y $C L_{50}$ elevados (hasta $>5000 \mathrm{mg} / \mathrm{L}$ ), como posible resultado de las condiciones imperantes en el ecosistema. De manera general, el $\mathrm{Cr}^{+6}$ fue el metal más tóxico, con mayor efecto de $\mathrm{Cr}^{+3}$ y $\mathrm{Pb}^{+2}$ en el Sitio $1(\mathrm{p}<0,05)$. El efecto de los metales sobre el crecimiento bacteriano fue: $\mathrm{Cr}^{+6}>\mathrm{Cd}^{+2}>\mathrm{Ni}^{+2}>\mathrm{Cr}^{+3}>\mathrm{Pb}^{+2}$. Debido a los altos niveles de resistencia y posible sobrestimación de la tolerancia en los ensayos, las bacterias no fungen como un grupo microbiano potencial para ser usadas como bioindicadores en programas de monitoreo ambiental para este ecosistema.

Palabras clave: bacterias pelágicas, concentración mínima inhibitoria, eutroficación, índice ecotoxicológico, resistencia bacteriana.

Abstract

Pollution of the Maracaibo Lake (Venezuela) estuarine system represents a long-standing environmental problem that has turned it into a hypereutrophic environment affected by different sources of pollution, which exerts strong selection pressure on the organisms living there. This paper compares heavy metal $\left(\mathrm{Cr}^{+3}, \mathrm{Cr}^{+6}, \mathrm{Cd}^{+2}, \mathrm{Ni}^{+2}\right.$ and $\left.\mathrm{Pb}^{+2}\right)$ ecotoxicity on heterotrophic bacteria from two sites at the Maracaibo Lake: 1) Vereda del Lago and 2) Puerto Concha, estimating minimum inhibitory concentration (MIC) and inhibition concentration for $50 \%$ of the studied population $\left(L C_{50}\right)$. For this purpose, the disk-diffusion agar method was used, measuring the halo of growth inhibition after $24 \mathrm{~h}$. $L C_{50}$ estimates were made by Probit analysis. Bacterial strains isolated from surface water showed high resistance to the heavy metals tested, with elevated MIC and $\mathrm{LC}_{50}$ values (up to $>5000 \mathrm{mg} / \mathrm{L}$ ), possibly due to prevailing ecosystem conditions. Generally, $\mathrm{Cr}^{+6}$ was the most toxic metal and $\mathrm{Cr}^{+3}$ and $\mathrm{Pb}^{+2}$ had $a$ higher effect on Site $1(p<0.05)$. The effect of metals on bacterial growth was $\mathrm{Cr}^{+6}>\mathrm{Cd}^{+2}>\mathrm{Ni}^{+2}>\mathrm{Cr}^{+3}>\mathrm{Pb}^{+2}$. Because of the high resistance levels and a possible overestimation of tolerance in the assays, bacteria do not function as a potential microbial group to be used as bioindicators in monitoring environmental programs for this ecosystem. 


\section{INTRODUCCIÓN}

La contaminación ambiental por metales pesados se ha extendido en todo el mundo junto con el progreso industrial. Este provoca que gran cantidad de elementos tales como cromo $(\mathrm{Cr})$, cadmio (Cd), níquel (Ni) y plomo ( $\mathrm{Pb}$ ) se abran camino hacia las grandes masas de agua a través de ríos, aguas residuales, escorrentías superficiales, percolación del suelo, deposición atmosférica y sistemas de drenajes, entre otros (Mohiuddin et al., 2010; Beyer et al., 2014; Bjerregaard et al., 2015; Limcharoensuk et al., 2015). Los residuos procedentes de la minería, las industrias de refinación de metales, las centrales eléctricas, las plantas de incineración de residuos y las operaciones de producción y transporte de petróleo, así como los depósitos de aguas residuales, suelen contener niveles sustancialmente elevados de $\mathrm{Pb}, \mathrm{Cr}$ y $\mathrm{Cd}$, lo cual representa una seria amenaza para la biota debido a su alta toxicidad. El Ni, por su parte, es un elemento esencial para el crecimiento microbiano, pero a altas concentraciones resulta tóxico. Este metal se genera en operaciones de minería y fundición de metales (Díaz-Borrego et al., 2007; Marrero-Coto et al., 2010; Naik y Dubey, 2013; Beyer et al., 2014; Frankel et al., 2016; Oyetibo et al., 2017).

La presencia de metales pesados en el medio ejerce una fuerte presión de selección sobre los organismos que lo habitan, de modo que puede modificar la flora microbiana autóctona del ecosistema (Cervantes y Vaca, 1990; Montuelle et al., 1994). Si la descarga del contaminante es de carácter permanente, como sucede habitualmente con estos elementos, se produce una selección de aquellos genotipos que pueden sobrellevar dicho estrés (Silver y Walderharg, 1992). La relación contaminante-microorganismo origina una serie de procesos adaptativos que finalmente se expresan como mecanismos de resistencia hacia el contaminante (Anisimova et al., 1993; Montuelle et al., 1994; Marrero-Coto et al., 2010; Poirier et al., 2013; Gillan, 2016).

El monitoreo de metales pesados en el ambiente permite establecer rutas de exposición hacia humanos (Alama et al., 2002), debido a que estos pueden bioacumularse y movilizarse a través de la cadena trófica (Páez y Frías, 2001). Por lo tanto, dada la toxicidad de muchos de aquellos y a que las determinaciones fisicoquímicas no resultan suficientes para valorar sus efectos potenciales sobre la vida acuática, se hace necesario conocer su efecto sobre las comunidades biológicas (APHA et al., 2005; Beyer et al., 2014; Bjerregaard et al., 2015). En ese sentido, los ensayos de ecotoxicidad son una herramienta potente para el reconocimiento de organismos indicadores de los impactos potenciales de contaminantes en ecosistemas acuáticos (Naik y Dubey, 2013; Poirier et al., 2013; Beyer et al., 2014; Bjerregaard et al., 2015).

El uso de bacterias acuáticas como bioindicadores de metales pesados en ambientes acuáticos está determinado por su capacidad de supervivencia en condiciones diversas y extremas (Zakaria et al., 2004; Sun et al., 2012; Poirier et al., 2013; De Vicente et al., 2017). La tolerancia bacteriana hacia metales pesados tóxicos puede deberse a dos factores (Volesky, 1990): i) la capacidad para resistir la presencia de alta concentración de metales en el citoplasma intracelular —es decir, bioacumulación-, ii) la precipitación/quelación del metal en la matriz exterior de la célula —es decir bioadsorción, que impide al metal llegar a los componentes intracelulares sensibles-. Los mecanismos de captación intracelular son metabólicamente mediados y se aplican solo a bacterias vivas, mientras que los extracelulares, o mecanismos de unión no específica, se producen con células muertas o moléculas de su descomposición (Zakaria et al., 2004; Marrero-Coto et al., 2010; Naik y Dubey, 2013; Beyer et al., 2014; Limcharoensuk et al., 2015).

Considerando lo anterior, el objetivo de este trabajo consistió en comparar la ecotoxicidad por metales pesados $\left(\mathrm{Cr}^{+3}, \mathrm{Cr}^{+6}, \mathrm{Cd}^{+2}, \mathrm{Ni}^{+2}\right.$ y $\left.\mathrm{Pb}^{+2}\right)$ sobre bacterias heterótrofas de dos sitios contrastados del lago de Maracaibo (Venezuela) mediante la estimación de la concentración mínima inhibitoria (CMI) y la concentración de inhibición para el $50 \%$ de la población de ensayo $\left(\mathrm{CL}_{50}\right)$. El presente constituye el primer reporte de $\mathrm{CL}_{50}$ para bacterias aisladas del lago de Maracaibo.

\section{MATERIALES Y MÉTODOS}

\section{Área y sitios de estudio}

El sistema Lago de Maracaibo se encuentra ubicado en el Noroeste de Venezuela y abarca todo el estado Zulia, parte de los estados Falcón, Trujillo, Lara y Mérida y parte de la República de Colombia, entre los $70^{\circ} 30^{\prime}$ y los $73^{\circ} 24^{\prime}$ de longitud $W$ y entre los $8^{\circ} 22^{\prime}$ y los $11^{\circ} 51^{\prime}$ de latitud Norte. Está conformado por el golfo de Venezuela, la bahía El Tablazo, el estrecho de Maracaibo, el lago propiamente dicho y los ríos tributarios. Esta cuenca hidrográfica tiene una extensión de 89756 km², 12013 km² correspondientes al lago de Maracaibo propiamente dicho. Este último presenta una profundidad media de $20 \mathrm{~m}$ y una máxima de $34 \mathrm{~m}$, una longitud de $152 \mathrm{~km}$, de los cuales $40 \mathrm{~km}$ pertenecen al estrecho de Maracaibo, un ancho promedio de $78 \mathrm{~km}$ y una temperatura que exhibe muy pocas variaciones, cuyo valor medio es de $28^{\circ} \mathrm{C}$ (Parra-Pardi, 1979; Herman, 1997; Gardner et al.. 1998; Rodríguez, 2000; Ávila et al., 2010).

El lago está emplazado en una depresión sedimentaria casi completamente rodeada de montañas de alturas y características fisiográficas variables. Abarca por el Sur y el Sureste los flancos de la cordillera de los Andes; por el Oeste y el Noroeste, la sierra de Perijá, y por el Este las estribaciones de la serranía de Coro (Herrera, 2004). El lago es un estuario parcialmente mezclado y naturalmente eutrófico. Sin embargo, el estado actual de hipertrofia es causado principalmente por las descargas descontroladas de aguas residuales, tratadas y no tratadas, desechos industriales, fuentes fluviales y agrícolas, así como por la contaminación atmosférica (Rivas et al., 2000; Rodríguez, 2000; Ledo et al., 2004; Ávila et al., 2010; Marín-Leal et al., 2017). 
Esta cuenca tiene las mayores reservas de petróleo de América del Sur y una de las más grandes del mundo, con una cantidad total de 33000 millones de barriles extraídos entre 1914 y 1995, la mayoría de los cuales proceden del fondo del lago (Rodríguez, 2000). Asimismo, se ha reportado el fenómeno de bioacumulación de metales pesados en la cadena trófica de este cuerpo de agua (Colina y Romero, 1992; Hermoso y Márquez, 2005; Rojas, 2012; Marín-Leal et al. 2017) como resultado del ingreso de estos elementos desde diferentes fuentes naturales y antropogénicas.

Para el presente estudio se seleccionaron dos sitios contrastados en el Lago de Maracaibo por su ubicación, actividades asociadas, área de influencia y accesibilidad (Fig. 1).

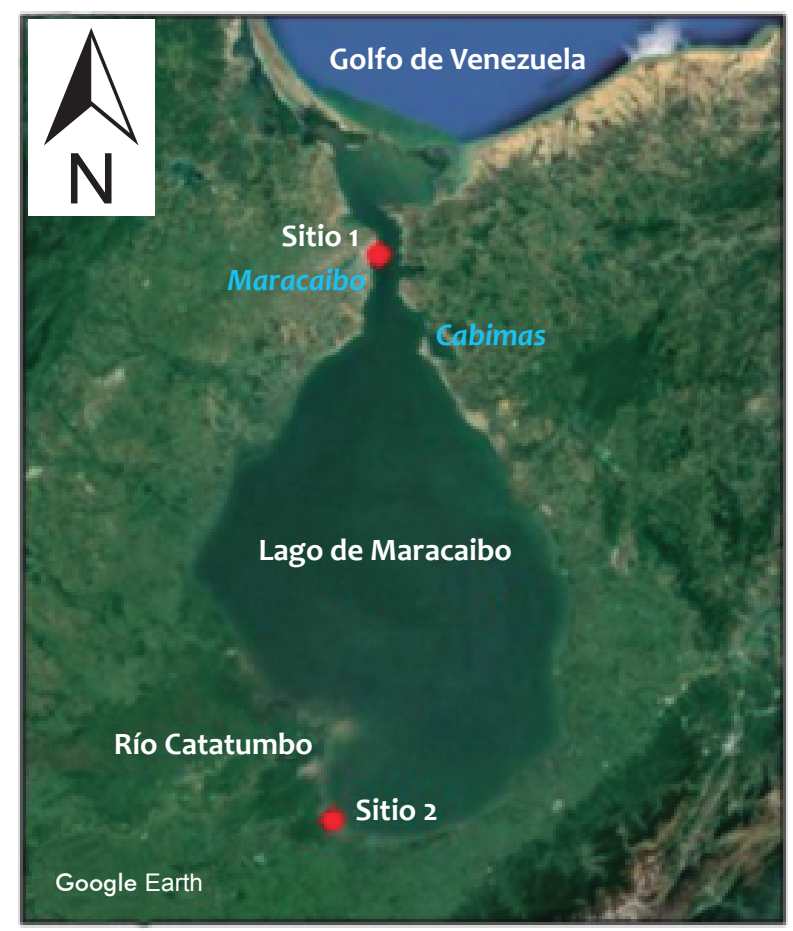

Figura 1. Ubicación de los sitios de estudio en el sistema lago de Maracaibo (Venezuela).

\section{Sitio 1}

Vereda del Lago de la ciudad de Maracaibo, al Norte del estrecho de Maracaibo, a los 10³9'29,69" latitud N y $71^{\circ} 35^{\prime} 22,02$ " longitud W. Esta zona recibe la descarga constante de aguas residuales domésticas e industriales (tenerías, mataderos, petróleo y gas, metalmecánicas, etc.), tratadas y no tratadas, de grandes ciudades como Maracaibo, Puertos de Altagracia, Santa Rita, Cabimas, entre otras, y sirve como ruta marítima para los buques que ingresan al lago a través del canal de navegación para abastecerse de petróleo. Además, por esta última razón el lago es dragado constantemente para garantizar las profundidades requeridas por los barcos tanqueros (Herman, 1997; De Bautista et al., 1999). En esta misma área se encuentra ubicado el Complejo Petroquímico El Tablazo, que alberga plantas de gas licuado, olefinas, cloro-soda, urea, amoniaco, vinilos, PVC, electricidad y otras empresas mixtas.

\section{Sitio 2}

Puerto Concha, al Sur del Lago de Maracaibo, a los $9^{\circ} 5^{\prime} 31,90^{\prime \prime}$ latitud N y $71^{\circ} 42^{\prime} 23,81^{\prime \prime}$ longitud W. Esta zona recibe los impactos de las áreas de drenaje de los principales ríos tributarios del sistema: Catatumbo, Santa Ana, Escalante, Bravo, Birimbay, Chama, entre otros, que aportan desechos principalmente de la industria agrícola, pecuaria y minera, así como domésticos (Ledo et al., 2004; Hermoso y Márquez, 2005; Rivas et al., 2005; Rivas et al., 2009). Esta zona también recibe los efectos de una fuerte actividad petrolera en el vecino país de Colombia, como resultado del sabotaje de los oleoductos por parte de la actividad guerrillera, que afecta principalmente al río Catatumbo, el cual aporta aproximadamente el $70 \%$ del agua dulce del sistema del lago de Maracaibo (Parra-Pardi, 1979; Ledo et al., 2004; Rivas et al., 2000).

\section{Muestreo y análisis de muestras}

En cada sitio de estudio se realizaron tres muestreos independientes de agua y sedimento superficiales durante 2016. En cada ocasión se recolectaba una muestra de agua de aproximadamente $500 \mathrm{~mL}$ en botellas plásticas de PVC y una de sedimento de $250 \mathrm{~g}$ (draga Ekman) en bolsas plásticas con cierre hermético. Adicionalmente, se recolectaban alícuotas de agua superficial en botellas de $250 \mathrm{~mL}$ de vidrio con tapa de baquelita y estériles para el aislamiento de bacterias heterótrofas. Estas muestras eran transportadas inmediatamente al laboratorio, bajo refrigeración, para iniciar los análisis fisicoquímicos y microbiológicos correspondientes, manteniéndose congeladas $\left(-10{ }^{\circ} \mathrm{C}\right)$ en sus envases cuando era necesario.

En el agua superficial de cada sitio se analizaron in situ: temperatura, $\mathrm{pH}$, oxígeno disuelto, potencial redox, conductividad eléctrica, salinidad y sólidos disueltos totales (SDT), usando una sonda multiparamétrica Orion modelo 5 Star Plus, mientras que en el laboratorio se cuantificaron alcalinidad total y dureza total de acuerdo con los métodos estandarizados (APHA et al., 2005).

En las muestras de agua y sedimento se analizaron los contenidos totales de $\mathrm{Cr}, \mathrm{Cd}, \mathrm{Ni}$ y $\mathrm{Pb}$ por la técnica de espectrometría de absorción atómica (equipo Perkin-Elmer modelo3100)conhornodegrafito(equipo Perkin-Elmermodelo AS60), previa digestión ácida en un horno de microondas Milestone modelo Ethos 1. En las digestiones se usaron 50 $\mathrm{mL}$ de muestra de agua y $5 \mathrm{~mL}$ de $\mathrm{HNO}_{3}$ concentrado (Riedelde Haën, Alemania). Para los sedimentos se añadieron $5 \mathrm{~g}$ de muestra liofilizada (liofilizador Labconco modelo Freezone 6) y $5 \mathrm{~mL}$ de mezcla $\mathrm{HCl}-\mathrm{HNO}_{3}(4: 1)$.

\section{Revista FULTAD DE CIENCIAS BÅSICAS}


La metodología de análisis de metales pesados se validó mediante un estudio de recuperación sobre los siguientes materiales estándares de referencia certificados: sedimento estuarino 1646a del NIST (National Institute of Standards and Technology, Gaithersburg, MD, USA) y elementos traza en agua natural 1640 a del NIST. Los porcentajes de recuperación se encontraron dentro del rango normalmente aceptado (100 $\pm 5 \%$ ), lo que indica la buena exactitud del método de análisis. Por otra parte, la precisión expresada como desviación estándar relativa se ubicó por debajo de $5 \%$, lo que muestra un grado de variabilidad aceptable en las repeticiones de los análisis (Rubinson y Rubinson, 2000).

\section{Aislamiento e identificación de bacterias heterótrofas}

Las muestras de agua destinadas al aislamiento de bacterias fueron sembradas en agar nutriente (Hi-Media Laboratories, India) mediante diluciones seriadas desde $10^{-2}$ hasta $10^{-9}$ (Reynolds, 2002; Rincón et al., 2007), empleando solución salina peptonada al 0,85\% previamente esterilizada. Las placas de Petri fueron llevadas a incubación bajo condiciones aerobias a $37 \pm 2{ }^{\circ} \mathrm{C}$ durante $24-48$ h. Con un contador Darfield (Québec, Canadá) se contaron las placas que presentaban un número de colonias entre 30 y 300 para expresar las unidades formadoras de colonias por mililitro de muestra (UFC/mL) (Rivera-Cruz et al., 2002; Madigan et al., 2004). De las colonias crecidas se seleccionó un $10 \%$ de acuerdo a las diferencias de forma, tamaño y aspecto para realizar aislamientos por rayado en placas con agar nutriente y obtener cultivos puros (Rincón et al., 2007).

Las cepas puras se codificaron y mantuvieron en caldo nutritivo (Hi-Media Laboratories, India), previa verificación con tinción de Gram, para entonces iniciar la identificación taxonómica mediante protocolos que incluyeron: descripción morfológica de las colonias (borde, espesor y forma) (Reynolds, 2002), tinciones diferenciales (tinción de Gram, tinción de esporas, tinción de cápsulas) y pruebas bioquímicas convencionales con cepas control (Holt et al., 1994; Murray et al., 1999; MacFaddin, 2004,).

\section{Ensayos ecotoxicológicos con bacterias heterótrofas}

Las pruebas de ecotoxicidad bacteriana por metales pesados se desarrollaron por el test de difusión en discos de papel sobre agar Muller Hinton (AMH, Merck, Alemania) para determinar la $\mathrm{CMI}$ y la $\mathrm{CL}_{50}$ (Fredrickson et al., 1988; Vásquez et al., 2005; Díaz-Borrego et al., 2007; Rathnayake et al., 2013). Inicialmente, las cepas fueron activadas en caldo nutriente por incubación a $37 \pm 2{ }^{\circ} \mathrm{C}$ durante $48 \pm 2 \mathrm{~h}$, para obtener una turbidez estandarizada de 0,5 unidades McFarland en el inóculo inicial de los ensayos (Martínez et al., 2010). Las placas de Petri (92 mm de diámetro) con AMH se inocularon por rayado con hisopos de algodón sobre toda la superficie en los ejes X, Y, Z y los bordes del agar para asegurar la distribución uniforme del inóculo y obtener un crecimiento confluente o en césped, distribuido homogéneamente. Los discos de papel de filtro estériles ( $6 \mathrm{~mm}$ de diámetro), similares a los que se utilizan para los antibiogramas, fueron impregnados con $10 \mu \mathrm{L}$ de la solución del metal a la concentración correspondiente, se colocaron sobre la biopelícula bacteriana de las placas de $\mathrm{AMH}$, presionando levemente para asegurar su contacto pleno, y se incubaron a $37 \pm 2{ }^{\circ} \mathrm{C}$ durante $24 \pm 2 \mathrm{~h}$.

Todos los ensayos fueron realizados por triplicado, colocando un máximo de tres discos por placa, incluidos discos sin soluciones de metales como control. Luego del periodo de incubación se midieron los halos de inhibición de crecimiento alrededor de los discos de papel usando un vernier. La CMI es la que produce un halo de inhibición de $10 \mathrm{~mm}$ (Fredrickson et al., 1988; Díaz-Borrego et al., 2007). Para los cálculos de $\mathrm{CL}_{50}$ se asumió el área de la placa como la población total y el halo de inhibición como la población afectada (calculando el área correspondiente al 50 \% de la población total) para el tiempo de exposición de $24 \mathrm{~h}$.

Para estimar la CMI se prepararon de 5 a 10 concentraciones diferentes de $\mathrm{Cr}^{+3}, \mathrm{Cr}^{+6}, \mathrm{Cd}^{+2}, \mathrm{Ni}^{+2}$ y $\mathrm{Pb}^{+2}$ en el rango de 50 a 5000 $\mathrm{mg} / \mathrm{L}$, dependiendo de los resultados que se iban obteniendo a partir de las sales de $\mathrm{CrCl}_{3} \cdot 6 \mathrm{H}_{2} \mathrm{O}$ (Riedel-de Haën, Alemania), $\mathrm{K}_{2} \mathrm{Cr}_{2} \mathrm{O}_{7}$ (Merck, Alemania), $\mathrm{CdCl}_{2}$ (Merck, Alemania), $\mathrm{Ni}_{2} \mathrm{SO}_{4}$ (Merck, Alemania) y $\mathrm{Pb}\left(\mathrm{NO}_{3}\right)_{2}$ (Merck, Alemania), respectivamente. A partir de estos resultados se prepararon las concentraciones necesarias para la estimación de $\mathrm{CL}_{50}$.

\section{Análisis estadísticos de datos}

Los cálculos de $\mathrm{CL}_{50}$ para cada cepa bacteriana se realizaron por análisis Probit usando el programa PriProbit versión 1.63 para obtener la concentración de metal que inhibe el crecimiento del 50 \% de la población del ensayo.

Se realizó un análisis de varianza (ANOVA) de una vía con el programa IBM SPSS Statistics versión 20, para determinar las diferencias significativas de $\mathrm{CMI}, \mathrm{CL}_{50}$, parámetros fisicoquímicos y contenidos de metales entre los sitios de estudio. Adicionalmente, se estableció un estudio de correlación de Pearson para conocer la correspondencia entre las diferentes variables en cada sitio de muestreo. En la serie de datos se comprobó tanto la homogeneidad de las varianzas (test de Levene) como la distribución normal de los residuos (test de Shapiro-Wilk), requiriéndose la transformación $\log _{10}$ para cumplir con los supuestos estadísticos.

\section{RESULTADOS Y DISCUSIÓN}

\section{Características fisicoquímicas de agua y sedimento super- ficiales}

En la Tabla 1 se presentan los resultados de la caracterización fisicoquímica y el contenido de metales pesados en agua y sedimento de los dos sitios estudiados en el Lago de Maracaibo. Estos valores son consistentes con los reportados en estudios anteriores para este mismo ecosistema (Parra-Pardi, 1979; Gardner et al., 1998; Rodríguez, 2000; Rincón et al., 2007; Marín et al., 2014; Marín-Leal et al., 2017). En cuanto a las concentraciones de los metales pesados 
los datos son comparables a los encontrados por Ávila et al. (2010) en sedimentos del lago, con 16,76-177,62 mg Ni/kg y 3,98-98-28 mg Cr/kg, y por Rojas (2012) en agua, con 6,738$8,156 \mu \mathrm{g} \mathrm{Cr} / \mathrm{L}$, mientras que los de $\mathrm{Pb}$ y $\mathrm{Cd}$ son mayores a los observados por estos autores, posiblemente debido a fuentes puntuales de vertido o a características locales de los sitios muestreados.

\begin{tabular}{|c|c|c|c|c|}
\hline \multirow[t]{2}{*}{ Parámetro } & \multicolumn{2}{|c|}{ Sitio 1} & \multicolumn{2}{|c|}{ Sitio 2} \\
\hline & Agua & Sedimento & Agua & Sedimento \\
\hline $\begin{array}{c}\text { Temperatura } \\
\left({ }^{\circ} \mathrm{C}\right)\end{array}$ & $29,7 \pm 1,2$ & - & $30,8 \pm 0,8$ & - \\
\hline $\mathrm{pH}$ & $8,08 \pm 0,33$ & - & $8,38 \pm 0,17$ & - \\
\hline $\begin{array}{c}\text { Oxígeno } \\
\text { disuelto }(\mathrm{mg} / \mathrm{L})\end{array}$ & $3,82 \pm 0,48$ & - & $4,01 \pm 0,49$ & - \\
\hline $\begin{array}{l}\text { Potencial } \\
\text { redox }(\mathrm{mV})\end{array}$ & $-61,74 \pm 14,01$ & - & $-80,22 \pm 3,49$ & - \\
\hline Salinidad (UPS) & $4,23 \pm 0,42$ & - & $3,31 \pm 0,14$ & - \\
\hline $\begin{array}{l}\text { Conductividad } \\
\text { eléctrica (mS/ } \\
\qquad \mathrm{cm})^{*}\end{array}$ & $7,64 \pm 0,07$ & - & $6,05 \pm 0,18$ & - \\
\hline $\begin{array}{c}\text { Sólidos } \\
\text { disueltos totales } \\
(\mathrm{mg} / \mathrm{L})^{*}\end{array}$ & $3745,1 \pm 35,0$ & - & $2900,9 \pm 50,4$ & - \\
\hline $\begin{array}{l}\text { Alcalinidad total } \\
\left(\mathrm{mg} \mathrm{CaCO}_{3} / \mathrm{L}\right)\end{array}$ & $47,5 \pm 12,9$ & - & $41,7 \pm 5,8$ & - \\
\hline $\begin{array}{l}\text { Dureza total } \\
\left(\mathrm{mg} \mathrm{CaCO}_{3} / \mathrm{L}\right)^{*}\end{array}$ & $786,3 \pm 105,1$ & - & $546,3 \pm 41,5$ & - \\
\hline $\mathrm{Cr} * *$ & $9,751 \pm 2,647$ & $18,56 \pm 4,92$ & $11,608 \pm 8,922$ & $19,34 \pm 6,30$ \\
\hline $\mathrm{Cd}^{* *}$ & $9,967 \pm 0,032$ & $18,03 \pm 0,29$ & $9,632 \pm 0,026$ & $18,03 \pm 0,53$ \\
\hline $\mathrm{Ni}^{* *}$ & $21,245 \pm 5,798$ & $23,40 \pm 6,43$ & $19,286 \pm 7,245$ & $23,79 \pm 4,54$ \\
\hline $\mathrm{Pb}^{* *}$ & $27,926 \pm 11,805$ & $38,98 \pm 12,78$ & $22,295 \pm 7,242$ & $43,33 \pm 10,18$ \\
\hline
\end{tabular}

Las diferencias contrastantes entre los dos sitios de muestreo seleccionados para este estudio fueron particularmente notorias con relación a los parámetros (Tabla 1): conductividad eléctrica, sólidos disueltos totales y dureza total $(p<0,05)$. Los contenidos de metales en agua y sedimento no fueron significativamente diferentes entre los sitios ( $p>0,05)$. Quedan así en evidencia las abundantes y diferentes fuentes de contaminación por estos elementos en la cuenca del lago de Maracaibo.

\section{Bacterias heterótrofas presentes en los sitios de estudio}

En las muestras de agua del lago de Maracaibo se obtuvieron recuentos de bacterias heterótrofas entre $5,2 \times 10^{4}$ y $8,3 \times 10^{6} \mathrm{UFC} / \mathrm{mL}$. No se observaron diferencias significativas en las densidades bacterianas entre los sitios de muestreo $(p>0,05)$. Del total de colonias crecidas inicialmente en agar nutriente se lograron aislar e identificar 20 cepas bacterianas, 10 en cada sitio de estudio, las cuales se agruparon en 8 familias y 13 géneros. La familia más numerosa fue Enterobacteriaceae con 6 géneros ( $46,15 \%$ ), observándose un $50 \%$ de abundancia para el Sitio 1 y $60 \%$ para el Sitio 2, lo que confirma la continuidad del proceso de contaminación fecal señalado para este estuario en muchas investigaciones previas (Rivas et al., 2005; Díaz-Borrego et al., 2007; Rincón et al., 2007; Bracho et al., 2009; Marín et al., 2014). Las otras familias representadas fueron: Pseudomonadaceae, Bacillaceae, Alcaligenaceae, Aeromonadaceae, Xanthomodaceae, Halomonadaceae y Moraxellaceae (Tabla 2). La segunda familia más numerosa fue Moraxellaceae (20\%), particularmente en el Sitio 2 (2 especies).

Tabla 2. Distribución porcentual (\%) de géneros bacterianos aislados de muestras de agua superficial de los dos sitios de estudio en el lago de Maracaibo (Venezuela).

\begin{tabular}{cccc}
\hline Familia & Género & Sitio 1 & Sitio 2 \\
\hline Enterobacteriaceae & Salmonella & 0 & 10 \\
& Enterobacter & 0 & 20 \\
& Proteus & 10 & 0 \\
& Citrobacter & 20 & 10 \\
& Escherichia & 10 & 10 \\
Pseudomonadaceae & Pantoea & 10 & 10 \\
Bacillaceae & Pseudomonas & 10 & 0 \\
Alcaligenaceae & Bacillus & 10 & 0 \\
Aeromonadaceae & Bordetella & 0 & 10 \\
Xanthomodaceae & Aeromonas & 10 & 0 \\
Halomonadaceae & Stenotrophomonas & 0 & 10 \\
Moraxellaceae & Halomonas & 10 & 0 \\
\hline
\end{tabular}

Todas las cepas bacterianas estuvieron conformadas por bacilos Gram - (Tabla 2), a excepción de los géneros Bacillus (bacilo Gram +), Bordetella (cocobacilo Gram -) y Acinetobacter (cocobacilo Gram -), de acuerdo a lo reportado en trabajos sobre resistencia bacteriana por Akhavan et al. (2015) y Moraga et al. (2003), para muestras de aguas residuales industriales (Irán) y de la bahía de Iquique (Chile), respectivamente.

De los 13 géneros identificados (Tabla 2), ocho han sido reportados previamente por otros autores para muestras de agua y sedimento del lago de Maracaibo: Aeromonas, Pseudomonas, Enterobacter, Escherichia, Salmonella, Proteus, Citrobacter y Bacillus (Dupontt et al., 2001; Díaz-Borrego et al., 2007; Rincón et al., 2007; Bracho et al., 2009). No obstante, no se encontraron reportes sobre la presencia de Pantoea, Acinetobacter, Bordetella, Stenotrophomona y Halomonas, que se aislaron por primera vez en este trabajo.

\section{Resistencia bacteriana a metales pesados}

Las CMI para las cepas bacterianas heterótrofas aisladas de agua superficial del lago de Maracaibo fueron particularmente elevadas: 3750 y $>5000 \mathrm{mg} \mathrm{Cr} / 3 / \mathrm{L}, 200$ y $>5000 \mathrm{mg} \mathrm{Cr}^{+6} / \mathrm{L}, 75 \mathrm{y}>5000 \mathrm{mg} \mathrm{Cd}^{+2} / \mathrm{L}, 2500$ y $>5000 \mathrm{mg} \mathrm{Ni}^{+2} / \mathrm{L}$ $y>5000 \mathrm{mg} \mathrm{Pb}^{+2} / \mathrm{L}$ para todas las cepas (Tabla 3). De manera general, las bacterias fueron más sensibles a la presencia de $\mathrm{Cr}^{+6}$ y más tolerantes a $\mathrm{Pb}^{+2}$, sin diferencias significativas entre los sitios de estudio ( $p>0,05)$. 
Tabla 3. Concentraciones mínimas inhibitorias (CMI) de metales pesados sobre el crecimiento de bacterias heterótrofas del lago de Maracaibo.

\begin{tabular}{|c|c|c|c|c|c|c|}
\hline \multirow[t]{2}{*}{ Sitio } & \multirow[t]{2}{*}{ Género } & \multicolumn{5}{|c|}{ Metal (mg/L) } \\
\hline & & $\mathrm{Cr}+3$ & $\mathrm{Cr}+6$ & $\mathrm{Cd}+2$ & $\mathrm{Ni}+2$ & $\mathrm{~Pb}+2$ \\
\hline \multirow[t]{10}{*}{1} & Pantoea & $>5000$ & 2500 & 5000 & $>5000$ & $>5000$ \\
\hline & Escherichia & $>5000$ & 315 & 2500 & $>5000$ & $>5000$ \\
\hline & Pseudomonas & $>5000$ & 2000 & $>5000$ & $>5000$ & $>5000$ \\
\hline & Citrobacter LM4 & $>5000$ & 4500 & $>5000$ & $>5000$ & $>5000$ \\
\hline & Bacillus & 5000 & 200 & 315 & 2500 & $>5000$ \\
\hline & Proteus & $>5000$ & 750 & 2500 & $>5000$ & $>5000$ \\
\hline & Citrobacter & $>5000$ & 500 & 2500 & $>5000$ & $>5000$ \\
\hline & Aeromona & $>5000$ & 500 & 2000 & $>5000$ & $>5000$ \\
\hline & Acinetobacter NO1 & 3750 & 550 & 2500 & 5000 & $>5000$ \\
\hline & Halomonas & $>5000$ & $>5000$ & 2000 & $>5000$ & $>5000$ \\
\hline \multirow[t]{10}{*}{2} & Salmonella & $>5000$ & 250 & $>5000$ & $>5000$ & $>5000$ \\
\hline & Bordetella & $>5000$ & 500 & $>5000$ & $>5000$ & $>5000$ \\
\hline & Enterobacter $\mathrm{LM}_{3}$ & $>5000$ & 500 & 2500 & $>5000$ & $>5000$ \\
\hline & Citrobacter LM4 & $>5000$ & 500 & 2500 & $>5000$ & $>5000$ \\
\hline & Escherichia & $>5000$ & 250 & $>5000$ & $>5000$ & $>5000$ \\
\hline & Stenotrophomona & $>5000$ & 1000 & 2500 & $>5000$ & $>5000$ \\
\hline & Acinetobacter LM10 & $>5000$ & 2000 & 75 & $>5000$ & $>5000$ \\
\hline & Enterobacter LM13 & $>5000$ & 2000 & 1000 & $>5000$ & $>5000$ \\
\hline & Acinetobacter LM14 & $>5000$ & 1000 & 5000 & $>5000$ & $>5000$ \\
\hline & Pantoea & $>5000$ & 2000 & 1000 & $>5000$ & $>5000$ \\
\hline
\end{tabular}

La resistencia a los metales pesados estudiados fue $<5000$ $\mathrm{mg} / \mathrm{L}$ en el $34 \%$ de los casos, mientras que solamente el $6 \%$ estuvo por debajo de $500 \mathrm{mg} / \mathrm{L}$. Bacillus sp. fue el género más sensible a estos metales (Tabla 3). En la literatura se han reportado amplios rangos de tolerancia para cepas bacterianas aisladas de diversos ecosistemas, como los presentados en la Tabla 4. En el caso de la bahía de Iquique (Chile), una vez considerados efluentes y muestras de suelos, entre otros, se han obtenido valores de CMI altos como respuesta de las bacterias a la descarga continua de metales en el ambiente, al igual que en el presente estudio.

Se obtuvieron correlaciones significativas entre los valores de CMI de las cepas bacterianas y las concentraciones de metales, tanto en agua como en sedimento de cada sitio de muestreo (considerando $r$ teórico=0,632, n=10 y $\mathrm{p}<0,05$ ), lo que sugiere que la descarga continua de estos elementos en el sistema ha generado impactos sobre estas poblaciones microbianas, tales como el desarrollo de mecanismos de tolerancia y resistencia (Anisimova et al., 1993; Montuelle et al., 1994; Marrero-Coto et al., 2010; Poirier et al., 2013; Gillan, 2016).

La aparición de cepas bacterianas resistentes a metales pesados en el Lago de Maracaibo está condicionada por las actividades de la industria petroquímica y otras que operan a sus alrededores, así como por los frecuentes derrames petroleros (Gardner et al., 1998). La acumulación gradual de cationes metálicos tanto en sitios antropogénicos como en ecosistemas naturales ha conducido al desarrollo de la homeostasis de metales pesados. Este fenómeno se debe a un proceso de adaptación espontánea al medio desarrollando o adquiriendo sistemas genéticos que contrarrestan los efectos de las elevadas concentraciones de iones metálicos en la célula (Marrero-Coto et al., 2010). Los mecanismos moleculares de resistencia bacteriana a metales pesados son diversos: captura de iones, transformaciones enzimáticas, expulsión de iones nocivos, excreción de sustancias poliméricas extracelulares, entre otros (Marrero-Coto et al., 2010; Naik y Dubey, 2013; Poirier et al., 2013; Gillan, 2016).

El test de difusión en discos de papel aplicado en el presente trabajo ha sido ampliamente usado para estimar los efectos de metales pesados sobre cepas bacterianas aisladas en diversos ecosistemas (Fredrickson et al., 1988; Vásquez et al., 2005; Dupontt et al., 2001; Moraga et al., 2003; DíazBorrego et al., 2007; Akhavan et al., 2015). No obstante, se ha encontrado que es posible obtener una sobrestimación de las concentraciones de tolerancia a los metales, como resultado de la formación de complejos o quelación de estos con los constituyentes orgánicos del medio de cultivo y la falta de estabilidad de los complejos metal-orgánicos (Rathnayake et al., 2013). Esto pudiera haberse presentado durante los ensayos de laboratorio.

Tabla 4. Comparación de concentración mínima inhibitoria (CMI) de las bacterias heterótrofas aisladas de dos sitios del lago de Maracaibo con las reportadas para otros ambientes.

\begin{tabular}{|c|c|c|c|c|}
\hline Bacteria & Sitio & Metal & $\mathrm{CMI}(\mathrm{mg} / \mathrm{L})$ & Referencia \\
\hline $\begin{array}{l}\text { Bacillus sp., Proteus sp., Enterobacter sp., } \\
\text { Citrobacter sp., Aeromonas sp., Pseudomonas sp. }\end{array}$ & Lago de Maracaibo, zona litoral & $\mathrm{Ni}^{+2}$ & $>2000$ & Díaz-Borrego et al., 2007 \\
\hline $\begin{array}{l}\text { Pseudomonas sp., } \\
\text { Alcaligenes sp. }\end{array}$ & $\begin{array}{l}\text { Bahía de Iquique } \\
\text { (Chile) }\end{array}$ & $\mathrm{Pb}^{+2}$ & $>3200$ & Moraga et al., 2003 \\
\hline Pseudomonas aeruginosa, Brevibacillus choshinensis & Efluente industria textilera (India) & $\mathrm{Cd}^{+2}$ & $>3300$ & Durve et al., 2012 \\
\hline Escherichia coli, Citrobacter sp., Klebsiella sp. & Aguas residuales industriales (Irán) & $\mathrm{Cr}^{+6}$ & $>1000$ & Akhavan et al., 2015 \\
\hline Streptomyces mirabilis (actinobacteria) & Suelo de una mina de uranio (Alemania) & $\mathrm{Ni}^{+2}$ & $>5800$ & Schmidt et al., 2009 \\
\hline Cepas MP1, MP2 y MP3 & Suelo de un campus universitario (India) & $\mathrm{Pb}^{+2}$ & $>4000$ & Krishna et al., 2012 \\
\hline Klebsiella sp. & Aguas residuales industriales (Irán) & $\mathrm{Cd}^{+2}$ & $>2400$ & Akhavan et al., 2015 \\
\hline Todos los géneros & Lago de Maracaibo, sitios 1 y 2 & $\mathrm{~Pb}^{+2}$ & $>5000$ & Este trabajo \\
\hline Enterobacter sp. & Lago de Maracaibo, Sitio 2 & $\mathrm{Cr}^{+6}$ & 2000 & Este trabajo \\
\hline Todos los géneros & Lago de Maracaibo, Sitio 2 & $\mathrm{Ni}^{+2}$ & $>5000$ & Este trabajo \\
\hline
\end{tabular}




\section{Ecotoxicidad bacteriana por metales pesados}

Los valores de $\mathrm{CL}_{50}$ para las diferentes cepas bacterianas aisladas de los dos sitios del lago de Maracaibo estuvieron

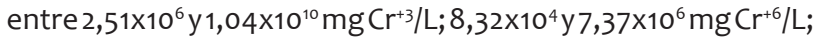
$3,9 \times 10^{5}$ y $1,13 \times 10^{8} \mathrm{mg} \mathrm{Cd} / 2 / \mathrm{L} ; 7,05 \times 10^{5}$ y $6,81 \times 10^{8} \mathrm{mg} \mathrm{Ni}^{+2} / \mathrm{L}$ y entre $2,67 \times 10^{6}$ y $1,93 \times 10^{12} \mathrm{mg} \mathrm{Pb}^{+2} / \mathrm{L}$. Tales valores son extremadamente elevados debido tanto al desarrollo de procesos de adaptabilidad como a la posible sobrestimación asociada al método de ensayo utilizado, de acuerdo a lo expuesto por Rathnayake et al. (2013). Sin embargo, aportan información concreta acerca del grado de tolerancia que exhiben las bacterias heterótrofas del lago de Maracaibo a los metales pesados, como resultado de la exposición prolongada y continua a través de las distintas vías de ingreso, tanto naturales como antropogénicas. Dicha tolerancia motiva el desarrollo del proceso de bioacumulación en las redes tróficas señalado para este ecosistema (Colina y Romero, 1992; Hermoso y Márquez, 2005; Rojas, 2012; MarínLeal et al., 2017).

En la Fig. 2 se presentan los valores generales de ecotoxicidad para las bacterias aisladas en los dos sitios de estudio como el inverso de la $\mathrm{CL}_{50}$, para facilitar la interpretación del efecto de los metales pesados como valores elevados de $1 / \mathrm{Cl}_{50}$ (De Vicente et al., 2017). Se

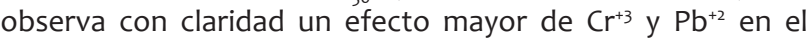
Sitio $1(p<0,05)$, como posible consecuencia de la variabilidad espacial en cuanto al aporte de las fuentes de metales pesados en la cuenca del Lago de Maracaibo y su efecto sobre las poblaciones microbianas locales.

Las cepas bacterianas obtenidas del Lago de Maracaibo mostraron patrones de multirresistencia a metales pesados, los cuales ocurren cuando los genes que especifican los fenotipos resistentes están localizados en elementos genéticos específicos —como plásmidos, transposones o integrones-, de acuerdo a lo sugerido por Chapman (2003). Se observaron correlaciones significativas entre los valores de $\mathrm{CL}_{50}$ de las cepas bacterianas y las concentraciones de metales en agua y sedimento de cada sitio de muestreo (considerando $r$ teórico $=0,632, n=10$ y $\mathrm{p}<0,05)$. De manera general, el metal más tóxico fue $\mathrm{Cr}^{+6}$, con el siguiente patrón de efecto sobre la población: $\mathrm{Cr}^{+6}>\mathrm{Cd}^{+2}>\mathrm{Ni}^{+2}>\mathrm{Cr}^{+3}>\mathrm{Pb}^{+2}$.

El efecto genotóxico de los metales pesados en bacterias resulta de la generación de estrés oxidativo a nivel celular, como producto de la reacción del oxígeno molecular con complejos metálicos generados a partir del glutatión. Dichos metales también tienden a unirse a grupos sulfhidrilo, lo que origina la inhibición de la actividad de enzimas sensibles y puede interrumpir ciertas funciones celulares suplantando a los iones fisiológicos comunes, como por ejemplo $\mathrm{Cd}^{+2}$ por $\mathrm{Zn}^{+2}$ y Ni$^{+2}$ por Fe ${ }^{+2}$ (Marrero-Coto et al., 2010; Bjerregaard et al., 2015).

Finalmente, queda por evaluar el efecto a largo plazo de las descargas de metales en la cuenca del Lago de Maracaibo sobre las poblaciones autóctonas de microorganismos, toda vez que las especies resistentes aparecidas pueden competir por la supervivencia y perpetuidad en este complejo estuario tropical. La dificultad de interpretación de los datos de $\mathrm{CL}_{50}$ para bacterias, aunada al alto grado de resistencia de estas, inviabiliza su utilización como posibles bioindicadores para el caso del Lago de Maracaibo, por lo que se recomienda estudiar otros grupos alternos de microorganismos.

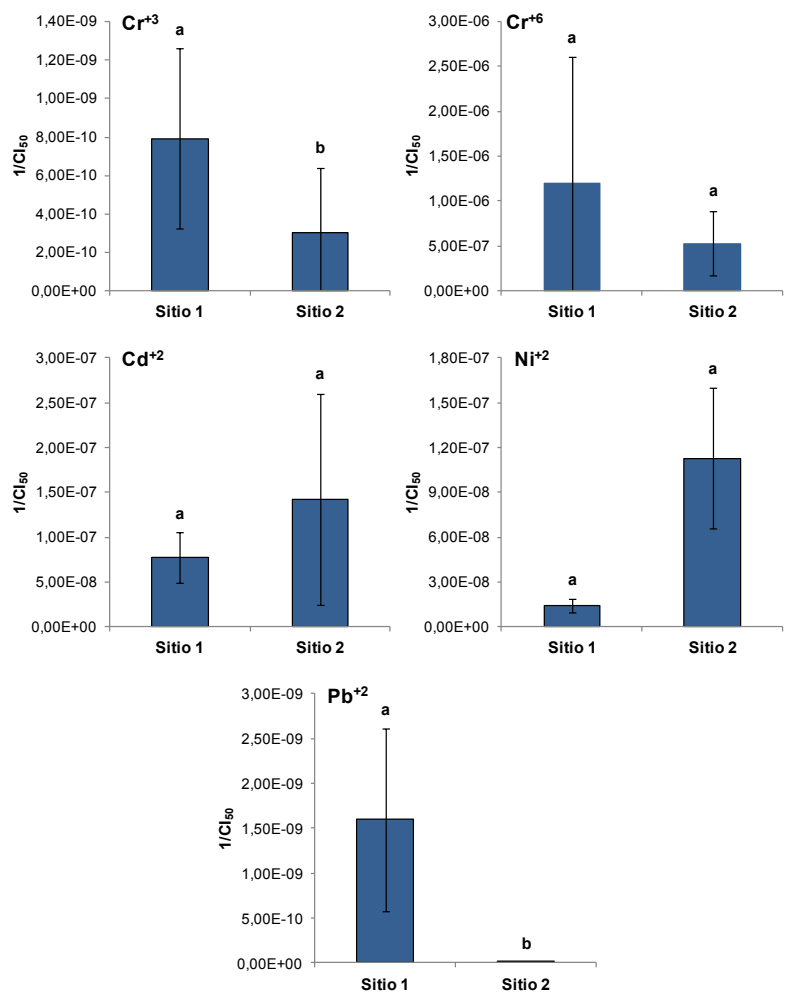

Figura 2. Niveles generales de ecotoxicidad $\left(1 / \mathrm{CL}_{50}\right)$ de metales pesados sobre bacterias heterótrofas de dos sitios contrastantes del lago de Maracaibo. Las barras verticales indican la media aritmética \pm desviación estándar para $n=10$. Letras diferentes para un mismo metal indican diferencias significativas entre los valores $(p<0,05)$.

\section{CONCLUSIONES}

Las cepas bacterianas aisladas de los dos sitios de estudio mostraron alta resistencia a los metales pesados ensayados, resultante posiblemente de su exposición a las crecientes condiciones de contaminación de este ecosistema. La cepa de Bacillus sp. fue el género más sensible a la presencia de los metales.

Se observaron diferencias intersitios y patrones de multirresistencia a los metales pesados, cuyo efecto fue: $\mathrm{Cr}^{+6}>\mathrm{Cd}^{+2}>\mathrm{Ni}^{+2}>\mathrm{Cr}^{+3}>\mathrm{Pb}^{+2}$, con mayor relevancia de $\mathrm{Cr}^{+3}$ y $\mathrm{Pb}^{+2}$ en el Sitio $1(p<0,05)$, favorecido probablemente por diferencias puntuales en cuando al aporte de las fuentes antropogénicas de metales.

Debido a los altos niveles de resistencia encontrados y a la dificultad de interpretación de los resultados de inhibición, las 
bacterias no fungen como un grupo microbiano de potencial uso como bioindicador en programas de monitoreo ambiental para este ecosistema.

Los valores de $\mathrm{CL}_{50}$ presentados pueden haber sido sobrestimados por factores asociados a la técnica de ensayo empleada, por lo que se recomienda interpretarlos cuidadosamente.

\section{AGRADECIMIENTOS}

Este trabajo fue co-financiado por el Consejo de Desarrollo Científico y Humanístico (Condes) de la Universidad del Zulia (Venezuela) y la Universidad de la Guajira (Colombia). Se agradece a la M. Sc. Cristina Rose Paredes Luengo por su participación durante la identificación taxonómica de las cepas bacterianas.

Conflicto de intereses: el manuscrito fue preparado y revisado con la participación de todos los autores, quienes declaramos que no existe ningún conflicto de intereses que ponga en riesgo la validez de los resultados presentados.

\section{REFERENCIAS}

- Akhavan S, Sharifian S, Zolfaghari M, Khalily D y Rashedi H. 2015. Study on heavy metal resistant fecal coliforms isolated from industrial, urban wastewater in Arak, Iran. Environmental Research, 9(4):1217-1224.

- Alama M, Tanakab A, Allinsona G, Laurensona L, Stagnittic F y Snowa E. 2002. A comparison of trace element concentrations in cultured and wild carp (Cyprinus carpio) of Lake Kasumigaura. Ecotoxicology and Environmental Safety, 53(3):348-354.

- Anisimova L, Siunova Ty Boronin A. 1993. Resistance to metals gram negative bacteria isolated from sewage and soils of industrials regions. Microbiology 62(5):505-508.

- APHA, AWWA y WEF. 2005. Standard methods for the examination of water and wastewater. 21th Edition, American Public Health Association Editorial, Washington, $1427 \mathrm{p}$.

- Ávila H, Gutiérrez E, Ledo H, Araújo M y Sánquiz M. 2010. Heavy metals distribution in superficial sediments of Maracaibo Lake (Venezuela). Revista Técnica de la Facultad de Ingeniería Universidad de Zulia, 33(2):122-129.

- Beyer J, Petersen K, Song Y, Ruus A, Grung M, Bakke T y Tollefsen KE. 2014. Environmental risk assessment of combined effects in aquatic ecotoxicology: A discussion paper. Marine Environmental Research, 96:81-91.

- Bjerregaard P, Andersen CBI y Andersen O. 2015. Ecotoxicology of metals: Sources, transport, and effects on the ecosystem. p. 425-459. En: Nordberg G, Fowler B y Nordberg M (Eds.). Handbook on the toxicology of metals. Elsevier Science, Ámsterdam, 612 p.

- Bracho M, Montiel M y Botero L. 2009. Virus entéricos, bacterias enteropatógenas y organismos indicadores de contaminación en camarones y en el agua y el sedimento de sus bancos naturales de producción. Ciencia, 17(1):14-24

- Cervantes C y Vaca S. 1990. Resistencia bacteriana a los metales pesados tóxicos. Ciencia y Desarrollo, 17(102):86-96.

- Chapman J. 2003. Disinfectant resistance mechanisms cross resistance, and co-resistance. International Biodeterioration and Biodegradation, 51:271-276.

- Colina M y Romero R. 1992. Mercury determination by cold vapor atomic absorption spectrometry in several biological indicators from Lake Maracaibo, Venezuela. Analyst, 117:645-647.

- De Bautista S, Bernard M, Romero M, Troncone F, Segovia S y Paredes J. 1999. Impacto ambiental de las descargas de mercurio en el canal de navegación del lago de Maracaibo. Revista Técnica de la Facultad de Ingeniería Universidad de Zulia, 22(1):42-50.

- De Vicente A, Olea F, Codina J, Arrebola E, Cazorla F y Pérez-García A. 2017. Resistencia bacteriana a metales y toxicidad como biomarcadores de la restauración de los suelos contaminados. Ciencia y restauración del río Guadiamar (España). http://www.juntadeandalucia.es/medioambiente/ consolidado/publicacionesdigitales, consulta febrero de 2017.
- Díaz-Borrego L, Dupontt J, Espina K, Rincón N, García M y Atencio L. 2007. Utilización de sustratos orgánicos y resistencia a metales pesados por bacterias asociadas a Lemna spp. Boletín del Centro de Investigaciones Biológicas, 41(1):27-43.

- Dupontt J, Díaz L, Atencio L y Pérez A. 2001. Susceptibilidad a $\mathrm{Hg}^{+2}$ y $\mathrm{Cd}^{+2}$ en cepas bacterianas biodegradadoras de antraceno aisladas de la playa "Caimare Chico", estado Zulia. Boletín del Centro de Investigaciones Biológicas, 35(3):242-258.

- Durve A, Naphade S, Bhot M, Varghese J y Chandra N. 2012. Characterisation of metal and xenobiotic resistance in bacteria isolated from textile effluent. Advances in Applied Science Research, 3(5):2801-2806.

- Frankel ML, Demeter MA, Lemire JA y Turner RJ. 2016. Evaluating the metal tolerance capacity of microbial communities isolated from Alberta oil sands process water. PLOS ONE, 11(2):1-15.

- Fredrickson JK, Hicks RJ, Li SW y Brockman F J. 1988. Plasmid incidence in bacteria from deep subsurface sediments. Applied and Environmental Microbiology, 54(12):2916-2923.

- Gardner W, Cavaletto J, Bootsma H, Lavrentyev P, Troncone F. 1998. Nitrogen cycling rates and light effects in tropical Lake Maracaibo, Venezuela. Limnology and Oceanography, 43(8):1814-1825.

- Gillan D. 2016. Metal resistance systems in cultivated bacteria: Are they found in complex communities? Current Opinion in Biotechnology, 38:123-130.

- Herman S. 1997. Proceso de salinización en el lago de Maracaibo. IclamCorpozulia, Maracaibo, 109 p.

- Hermoso D y Márquez M. 2005. Evaluación de las concentraciones de metales pesados en tejidos de peces del río Catatumbo y sus afluentes. Trabajo especial de grado, Universidad Rafael Urdaneta, Maracaibo. 116 p.

- Holt JG, Krieg NR, Sneath PHA, Staley JT y Williams ST. 1994. Bergey's manual of determinative bacteriology. Novena ed., Williams and Wilkins, Baltimore, $606 \mathrm{p}$.

- Krishna MP, Varghese R y Hatha M. 2012. Heavy metal tolerance patterns of total heterotrophic bacteria isolated from the soils of Mahatma Gandhi University campus, Kottayam, Kerala. Indian Journal of Innovations and Developments, 1(3):145-148.

- Ledo H, Rivas Z, Gutiérrez J, Gutiérrez E, Ojeda J y Ávila H. 2004. Baseline of $\mathrm{Ca}, \mathrm{Mg}, \mathrm{Fe}, \mathrm{Mn}$ and $\mathrm{Al}$ concentrations in Catatumbo river surficial sediments. Water, Air, and Soil Pollution, 155:117-135.

- Limcharoensuk T, Sooksawat N, Sumarnrote A, Awutpet T, Kruatrachue $M$ y Pokethitiyook P. 2015. Bioaccumulation and biosorption of $\mathrm{Cd}^{2+}$ and $\mathrm{Zn}^{2+}$ by bacteria isolated from a zinc mine in Thailand. Ecotoxicology and Environmental Safety, 122:322-330.

- MacFaddin J. 2004. Pruebas bioquímicas para la identificación de bacterias de importancia clínica. Tercera ed., Editorial Panamericana, Madrid, 850 p.

- Madigan M, Martinko J y Parker J. 2004. Brock Biología de los microorganismos. Novena ed., Prentice Hall, Madrid, 986 p.

- Marín J, Behling E, Chirino J, Medina K y Pirela MG. 2014. Calidad sanitaria de aguas recreacionales en el estrecho del lago de Maracaibo. Impacto Científico, 9(1):26-42

- Marín-Leal JC, Carrasquero-Ferrer SJ, Pire-Sierra MC y Behling de Calmón EH. 2017. Dynamic of priority pollutants and wastewater adequacy in the Lake Maracaibo basin (Venezuela). Chapter 29 (p. 457-479). Araújo CVM y Shinn C (Eds.). Ecotoxicology in Latin America. Nova Science Publishers Inc., Nueva York, $508 \mathrm{p}$.

- Marrero-Coto J, Díaz-Valdivia A y Coto-Pérez O. 2010. Mecanismos moleculares de resistencia a metales pesados en las bacterias y sus aplicaciones en la biorremediación. Revista Cenic Ciencias Biológicas, 41(1):67-78.

- Martínez A, Cruz M, Veranes O, Carball M, Salgado I, Olivares S, Lima L y Rodríguez D. 2010. Resistencia a antibióticos y a metales pesados en bacterias aisladas del río Almendares. Revista Cenic Ciencias Biológicas, 41:1-10.

- Mohiuddin K, Zakir H, Otomo K, Sharmin S y Shikazono N. 2010. Geochemical distribution of trace metal pollutants in water and sediments of downstream of an urban river. International Journal of Environmental Science and Technology, 7(1):17-28.

- Montuelle B, Latour X, Volat B y Gounet A. 1994. Toxicity of heavy metals to bacteria in sediments. Bulletin of Environmental Contamination and Toxicology, 53:753-758.

- Moraga R, Merino C y Mondaca MA. 2003. Resistencia a metales pesados en bacterias aisladas de la bahía de Iquique. Investigación Marina Valparaíso, 31(1):91-95.

- Murray P, Baron E, Pfaller M, Tenover F y Yolken R. 1999. Manual of clinical microbiology. Sexta ed., ASM Press, Washington, D. C., 1773 p. 
- Naik MM y Dubey SK. 2013. Lead resistant bacteria: Lead resistance mechanisms, their applications in lead bioremediation and biomonitoring. Ecotoxicology and Environmental Safety, 98:1-7.

- Oyetibo GO, Chien MF, Ikeda-Ohtsubo W, Suzuki H, Obayori OS, Adebusoye SA, Ilori MO, Amund $\mathrm{OO}$ y Endo G. 2017. Biodegradation of crude oil and phenanthrene by heavy metal resistant Bacillus subtilis isolated from a multipolluted industrial wastewater creek. International Biodeterioration and Biodegradation, 120:143-151.

- Páez F y Frías M. 2008. Bioacumulación, distribución y efectos de los metales pesados en los peneidos (p. 244-270). Páez F (Ed.). Camaronicultura y medio ambiente. Universidad de Texas, Austin, 545 p.

- Parra-Pardi G. 1979. Estudio integral sobre la contaminación del lago de Maracaibo y sus afluentes. Parte II: evaluación del proceso de eutroficación. Ministerio del Ambiente y de los Recursos Naturales Renovables, Caracas, 222 p.

- Poirier I, Hammannb P, Kuhnb L y Bertranda M. 2013. Strategies developed by the marine bacterium Pseudomonas fluorescens BA3SM1 to resist metals: A proteome analysis. Aquatic Toxicology, 128-129:215-232.

- Rathnayake IVN, Megharaj M, Krishnamurti GSR, Bolan NS y Naidu R. 2013. Heavy metal toxicity to bacteria - Are the existing growth media accurate enough to determine heavy metal toxicity? Chemosphere, 90:1195-1200.

- Reynolds J.2002. Laboratory procedures manual. Richland College, Dallas, 87 p.

- Rincón N, Dupontt J y Díaz-Borrego L. 2007. Bacterias y protozoarios ciliados de muestras de agua de la costa oriental del lago de Maracaibo. Boletín del Centro de Investigaciones Biológicas, 41(3):309-322.

- Rivas Z, Ledo H, Gutiérrez J y Gutiérrez E. 2000. Nitrogen and phosphorus levels in sediments from tropical Catatumbo river (Venezuela). Water, Air, and Soil Pollution, 117:27-37.

- Rivas Z, Márquez R, Troncone F, Sánchez J, Colina M y Hernández P. 2005. Contribución de principales ríos tributarios a la contaminación y eutrofización del lago de Maracaibo. Ciencia, 13(1):68-77.

- Rivas Z, Sánchez J, Troncone F, Márquez R, Ledo H, Colina M y Gutiérrez E. 2009. Nitrógeno y fósforo totales de los ríos tributarios al sistema lago de Maracaibo, Venezuela. Interciencia, 34(5):308-314.
- Rivera-Cruz M, Ferrera-Cerrato RV, Volke H, Rodríguez V y Fernández L. 2002. Adaptación y selección de microorganismos autóctonos en medios de cultivos enriquecidos con petróleo crudo. Terra, 20:423-434.

- Rodríguez G. 2000. El sistema de Maracaibo, biología y ambiente. Instituto Venezolano de Investigaciones Científicas (Ivic), Caracas, 241 p.

- Rojas J. 2012. Polymesoda solida como bioindicador de metales pesados en el sistema del lago de Maracaibo. Tesis de doctorado, Universidad del Zulia, Maracaibo, $250 \mathrm{p}$.

- Rubinson JF y Rubinson KA. 2000. Química analítica contemporánea. Prentice Hall, México, D. F., 644 p.

- Schmidt A, Haferburg G, Schmidt A, Lischke U, Merten D, Ghergel F, Büchel C y Kothe E. 2009. Heavy metal resistance to the extreme: Streptomyces strains from a former uranium mining area. Chemie der Erde, 69:35-44.

- Silver S y Walderharg M. 1992. Gene regulation of plasmid and chromosome determined inorganic ion transport in bacteria. Microbiological Reviews, 56(1):195-228.

- Sun MY, Dafforn K, Brown MV y Johnston EL. 2012. Bacterial communities are sensitive indicators of contaminant stress. Marine Pollution Bulletin, 64 (5):1029-1038.

- Vásquez R, Bastardo A y Mundarain I. 2005. Ensayo de toxicidad aguda $\mathrm{Cl}_{50}-96 \mathrm{~h}$ con acetato de cadmio y parámetros hematológicos en el híbrido cultivado Colossoma macropomum y Piaractus brachypomus. Zootecnia Tropical, 23(3):247-257.

- Volesky B. 1990. Biosorption of heavy metals. CRC Press, Boca Raton, 408 p.

- Zakaria ZA, Jaapar J y Ahmad WA. 2004. Bacteria as bioindicators for metal contamination (p. 131-135). Phang y Brown (Eds.). Biomonitoring in tropical coastal ecosystems. University of Malaysia Maritime Research Centre, Skudai, 328 p. 